\title{
ChemComm
}

CORRECTION

View Article Online

View Journal I View Issue

Check for updates

Cite this: Chem. Commun., 2018, 54, 9091

DOI: $10.1039 / c 8 c c 90347 f$

rsc.li/chemcomm

\section{Correction: PEG-nanotube liquid crystals as templates for construction of surfactant-free gold nanorods}

\author{
Naohiro Kameta (D)*a and Hidenobu Shiroishi (D) ${ }^{\mathrm{b}}$ \\ Correction for 'PEG-nanotube liquid crystals as templates for construction of surfactant-free gold \\ nanorods' by Naohiro Kameta et al., Chem. Commun., 2018, 54, 4665-4668.
}

The authors regret that an incorrect image was included in Fig. 1(b) of the original article and in Fig. S6 of the corresponding Electronic Supplementary Information. The correct version of Fig. 1 is presented below, and the ESI file available online has been replaced with an updated version.
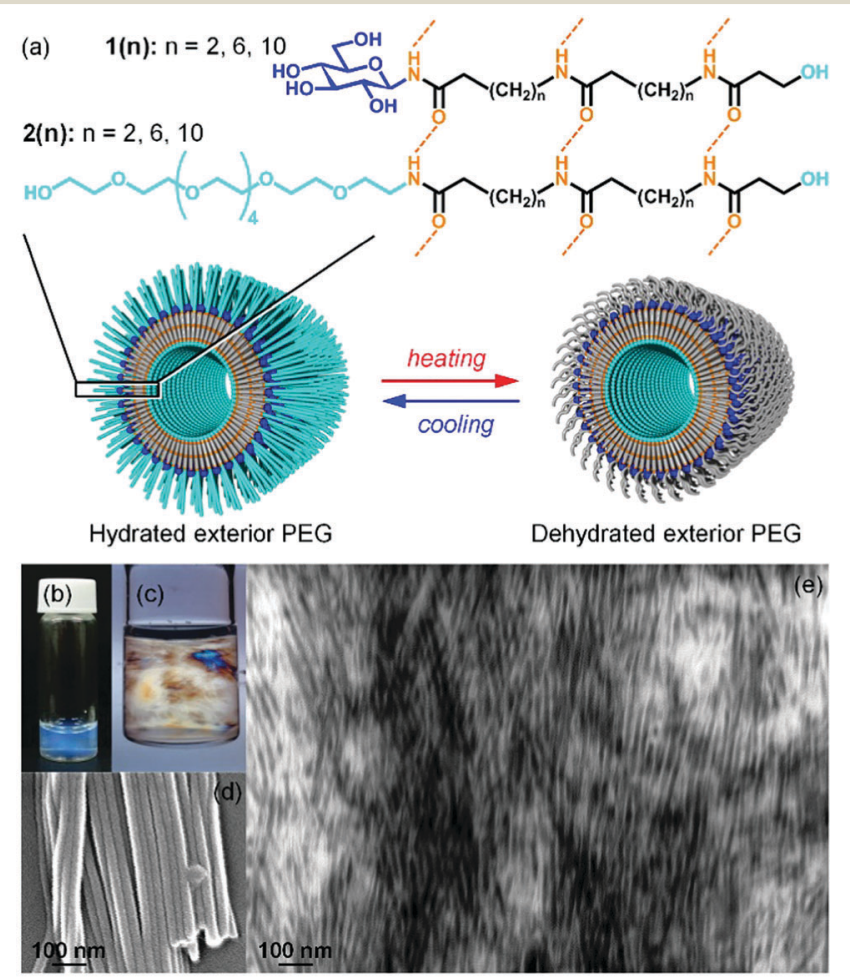

Fig. 1 (a) Schematic representation of PEG nanotubes formed by binary self-assembly of $\mathbf{1}(\mathbf{n})$ and $\mathbf{2}(\mathbf{n})$ and subsequent thermal dehydration and rehydration of the exterior PEG chains. (b and c) Photographs of NT-LCs composed of 1(2) and 2(2) obtained without (b) and with (c) a cross polarizer. (d) SEM and (e) TEM images of side-by-side aligned nanotubes in dry-state NT-LCs.

The Royal Society of Chemistry apologises for these errors and any consequent inconvenience to authors and readers.

\footnotetext{
${ }^{a}$ Nanomaterials Research Institute, Department of Materials and Chemistry, National Institute of Advanced Industrial Science and Technology (AIST), Tsukuba Central 5, 1-1-1 Higashi, Tsukuba, Ibaraki 305-8565, Japan. E-mail: n-kameta@aist.go.jp; Fax: +81-29-861-4545; Tel: +81-29-861-4478

${ }^{b}$ National Institute of Technology, Tokyo College, Kunugida 1220-2, Hachiouji, Tokyo, 193-0997, Japan
} 